\title{
Brackish water irrigation on the characteristics of carbon, nitrogen and phosphorus nutrients in the soil nearby crop roots
}

\author{
Yun $\mathrm{Li}^{1,2 *}$, Jiancang Xie', Rengui Jiang ${ }^{1}$ \\ ${ }^{1}$ Faculty of Water Resources and Hydroelectric Engineering, Xi'an University of Technology, Xi'an, 710048, China, '2iaocheng Municipal Water \\ Resources Bureau of Shandong Province, Liaocheng, 252000, China
}

\section{A B S TR A C T}

\begin{abstract}
To study the effect of brackish water on carbon, nitrogen and phosphorus in the soil nearby root zone of crops. By analyzing the influence of different levels of salt and fresh water combination irrigation on organic carbon, nitrogen and phosphorus migration rule in the soil, and the dynamic change rule in different sections to investigate the spatial distribution of each index at the end of the experiment. According to the soil properties and root distribution of Zizyphusjujuba, brackish water drip irrigation quota, irrigation water salinity and fertilization measures of root zone, different gradient levels of combined irrigation experiments were set up. The experiment with fresh water was used as control to establish orthogonal test scheme. The content of carbon, nitrogen and phosphorus in soil nearby crop roots was measured, and the measurement of carbon, nitrogen and phosphorus in the soil nearby crop roots was utilized to analyze the effect of brackish water irrigation on the soil nearby crop roots. With the increase of brackish water amount for irrigation, nitrate and alkali nitrogen content in the soil nearby roots was significantly decreased, and the reduction trend is going up after a significant amount of brackish water for irrigation is added. While phosphorus content decreased at different levels after brackish water amount for irrigation was increased, but the decrease is not significant. Brackish water irrigation with appropriate amount of salt can improve the effective utilization rate of carbon and nitrogen and phosphorus in soil, and result in higher yield for crops. The fruit set is the highest under brackish water irrigation with $3 \mathrm{~g} / \mathrm{L}$ salt.
\end{abstract}

Keywords: Brackish water; Carbon and nitrogen and phosphorus; Irrigation; Nutrients crops; Root zone; Soil

\section{INTRODUCTION}

Plants and soils are the main reservoirs of nutrients in ecosystems. The content of nutrients varies with the type of soil and plant species, and it is affected by external environmental factors to a certain extent. The content of nutrients in soil and its effectiveness are important chemical indicators in the ecosystem, affecting the growth and development of the plant (Kniat, 2017; Camara et al., 2018). Trace elements are key components of various enzymes, growth hormones and vitamins in plants and play an important role in plant growth and development as well. The trace elements such as iron, manganese, zinc, and copper that participate in various physiological metabolic activities in plants are mainly derived from the soil (Roy et al., 2018; Zhang et al., 2018; Ahamed et al., 2017; Li et al., 2018; Wang et al., 2018). The supply level of trace elements in the soil will affect the metabolic function of the plant. Carbon, nitrogen and phosphorus are the basic elements in the plant life and are important parts for the plant to achieve energy metabolism, genetic variation and information expression (Wang and Lu, 2014). The stoichiometric ratio is an important indicator of nutrients supplied by soil during plant growth. Therefore, the study of different kinds of mineral nutrients between plants and soils, and the discussion of nutrient transfer rules and plant nutrient restriction during the cycle of soil ecological chemistry are of great significance for revealing the adaptation mechanism of plants to the salty environment.

With the rapid economic development, the contradiction between the supply and demand of freshwater resources has become increasingly serious, and rational development of underground brackish water resources has gradually become the focus of attention of various countries. At present, many scholars at home and abroad have studied the

\footnotetext{
*Corresponding author:

Yun Li, Faculty of Water Resources and Hydroelectric Engineering, Xi'an University of Technology, Xi'an, 710048, China.

E-mail: liyun6168@aliyun. Com
}

Revised: 20 December 2017;

Accepted: 20 September 2018 
effects of brackish water irrigation methods and techniques and soil salinity on soil quality, crop yield and quality, and have obtained some results, which provide theoretical basis for the use of brackish water. Although the utilization of brackish water satisfies the demand for water at different stages of the crop, excessive brackish water irrigation will cause deterioration of the soil ecological environment and reduce crop yield and quality (Zhang and Wu, 2016). In order to avoid soil salinization caused by long-term brackish water irrigation, it is necessary to study the influence of brackish water on the characteristics of carbon, nitrogen and phosphorus in soil nearby crop roots, and to reduce the adverse effects on soil environment and plant growth after irrigation.

\section{MATERIALS AND METHODS}

This study mainly focuses on the effect of different levels of combined fresh-saline irrigation on the transport of organic carbon, nitrogen, and phosphorus in the soil. The experiment determines the content of organic carbon, nitrate nitrogen, alkali-hydrolyzed nitrogen and phosphorus in the soil nearby root zone of the jujube under brackish water irrigation conditions with various salt amount at different growth stage of the jujube, and studies its dynamic changes in different sections and analyze the spatial distribution of each measurement index at the end of the test (Chmelíková and Hejcman, 2014). Studying the impact of brackish water irrigation on soil fertility provides research data for field trials and establishes proper brackish water regulation irrigation measures.

\section{Overview of test area}

The experiment was conducted at the Water Saving Irrigation Experimentation Base at the department of Water Conservancy and Architectural Engineering in Tarim University, Alar City, Xinjiang, where the test area is the alluvial plain and belongs to a typical continental extreme desert climate ( $\mathrm{Li}$ and Lei, 2015). There is less rains and drought, annual rainfall is $50-70 \mathrm{~mm}$, annual evaporation is more than 1400-1700 mm, temperature difference between day and night is big, annual average hours with sunshine is $2729 \mathrm{~h}$, average temperature in the hottest month is $25-27^{\circ} \mathrm{C}$. January has the lowest temperature, mostly between -22 and $-30^{\circ} \mathrm{C}$. One year has a frost-free period of more than 200 days and a drought index of 7-20. The soil texture is sandy loam soil, the soil has good air permeability, the soil bulk density is $1.49 \mathrm{~g} / \mathrm{cm}^{3}$, the field water capacity is $28 \%$, the groundwater depth is below $3.8 \mathrm{~m}$ (negligible groundwater recharge).

\section{Experiment materials}

The material is a two-year-old grafted jujube tree, named Tianshan Junzao, provided by Agricultura Agronomian Alar
Company (Nystrand and Österholm, 2016). Dwarf planting method is used, the average plant height of jujube tree is 1-1. $5 \mathrm{~m}$, planting area is $18^{*} 15 \mathrm{~m}^{2}$, and plant distance is $1.5^{*} 2 \mathrm{~m}^{2}$.

\section{Treatment}

The orthogonal design test method is adopted. Three factors are all set at three levels and the orthogonal mode $\mathrm{L}_{9}\left(3^{3}\right)$ is selected. The field arrangement is randomly arranged with a total of 9 treatments. The isolation zone is set between each treatment and 2 repeated treatments. Two jujube trees with the same growth trend are selected for each treatment (Yadav et al., 2017; Gavin-Quinchuela et al., 2018). The control treatment consisted of 10L freshwater, 20L freshwater, and 30L freshwater, 2 replicates for each control, a total of 42 jujube trees are selected and numbered sequentially from 1 to 42 . The irrigation method is mainly drip. The water source is taken from the shallow groundwater in the test area. The salt content is $1.7 \mathrm{~g} / \mathrm{L}$, and the water is evaporated under the sunshine. Then, according to the test requirements, irrigation waters with different amount of salt are prepared. The drip irrigation method simulates a Marange flask for irrigation (Khajanchi and Minhas, 2015), as shown in Fig. 1. The flow rate is controlled at $2 \mathrm{~L} / \mathrm{h}$, taking into account the high evaporation intensity during the day, the irrigation time is set at night. According to the soil properties and root distribution of the jujube tree root area, brackish water drip irrigation quota, irrigation water salinity and fertilization measures of root zone (Shila et al., 2018; Anuar et al., 2018; Sathi et al., 2018), combined irrigation tests of different gradients are set up. Freshwater is used as a control to establish an orthogonal test plan, which as shown in Table 1, Table 2 and Table 3.

\section{Sampling}

The jujube trees are fertilized and irrigated once per each growth period and irrigated conventionally at other periods. After 24 hours of irrigation, soil samples are taken to

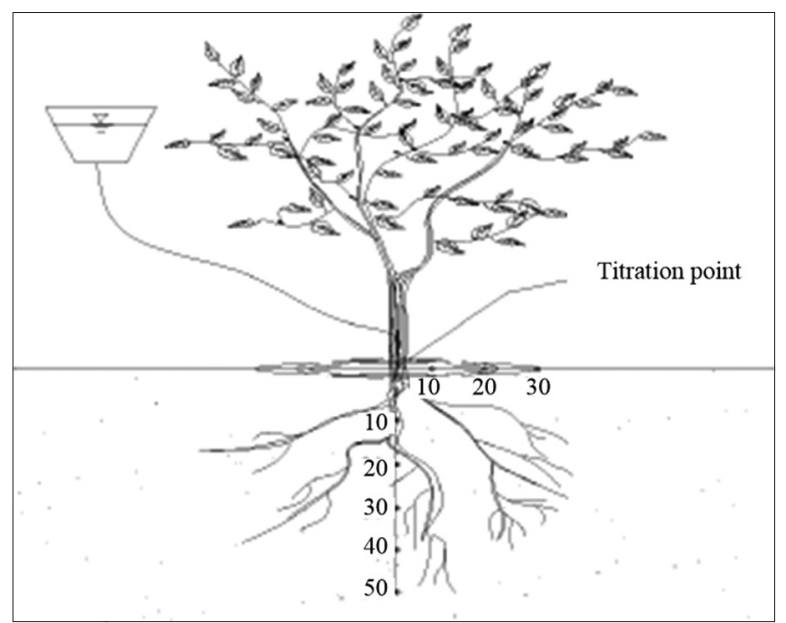

Fig 1. A sketch map of the drip irrigation and sampling point of jujube trees. 
Table 1: The fertilization scheme of jujube (unit: $\mathrm{kg} / 666.7 \mathrm{~m}^{2}$ )

\begin{tabular}{lcccc}
\hline Treatment level & $\mathbf{N}$ & $\begin{array}{c}\text { Fertilizer } \\
\boldsymbol{P}_{2} \boldsymbol{O}_{5}\end{array}$ & $\boldsymbol{K}_{2} \boldsymbol{O}$ & $\begin{array}{c}\text { Organic } \\
\text { manure } \boldsymbol{O M}_{1}\end{array}$ \\
\hline $\begin{array}{l}\text { Single application of } \\
\text { organic fertilizer } O M_{1}\end{array}$ & - & - & - & 1200 \\
$\begin{array}{l}\text { Conventional } \\
\text { fertilization }\end{array}$ & 80 & 50 & 70 & 1200 \\
$\begin{array}{l}\left(N P K+O M_{1}\right) \\
\begin{array}{l}\text { Optimal fertilization } \\
\left(N P K+O M_{1}\right)\end{array}\end{array}$ & 60 & 30 & 50 & 1200 \\
\hline
\end{tabular}

Table 2: Levels access Irrigation test project factors

\begin{tabular}{lccc}
\hline $\begin{array}{l}\text { Factors } \\
\text { Level }\end{array}$ & $\begin{array}{c}\text { Titration quota } \\
\text { (L/strain) }\end{array}$ & $\begin{array}{c}\text { Irrigation water } \\
\text { salinity }(\mathbf{g} / \mathbf{L})\end{array}$ & $\begin{array}{c}\text { Fertilizer rate } \\
(\mathbf{k g} / 66.7) \mathbf{m}^{2}\end{array}$ \\
\hline 1 & 10 & 2 & $O M_{1}$ \\
2 & 20 & 3 & CF \\
3 & 30 & 1 & OF \\
\hline
\end{tabular}

Table 3: Orthogonal experimental design scheme

\begin{tabular}{lccc}
$\begin{array}{l}\text { Dealing with } \\
\text { numbers }\end{array}$ & $\begin{array}{c}\text { Drip irrigation } \\
\text { quota }\end{array}$ & $\begin{array}{c}\text { Factors - irrigation } \\
\text { water salinity }\end{array}$ & $\begin{array}{c}\text { Fertilizer } \\
\text { rate }\end{array}$ \\
\hline 1 & 2 & 3 & 3 \\
2 & 2 & 1 & 1 \\
3 & 3 & 2 & 2 \\
4 & 1 & 2 & 2 \\
5 & 2 & 3 & 3 \\
6 & 3 & 1 & 1 \\
7 & 1 & 1 & 1 \\
8 & 2 & 3 & 2 \\
9 & 3 & 2 & 3 \\
\hline
\end{tabular}

determine the content of each element. The soil samples used for organic carbon, nitrate nitrogen, alkali-hydrolyzed nitrogen, and phosphorus measurement are collected vertically on May $17^{\text {th }}$, May $28^{\text {th }}$, June $28^{\text {th }}$, July $28^{\text {th }}$, and August $28^{\text {th }}$, corresponding to the early germination stage, the germination stage, flowering stage, fruit setting stage and fruit ripening stage (Kumari and Moldrup, 2014). The main absorbent root zone of the jujube tree is distributed in the range of $30-40 \mathrm{~cm}$ and the longest root system is up to $50 \mathrm{~cm}$. The samples are collected at $0-10 \mathrm{~cm}, 10-20 \mathrm{~cm}, 20-$ $30 \mathrm{~cm}, 30-40 \mathrm{~cm}, 40-50 \mathrm{~cm}$. The soil samples at the horizontal direction is taken at the end of the test, that is, on September $13^{\text {th }}$. The spatial distribution of each index is measured and compared with the control treatment test. The difference between the analysis and the control treatment is analyzed. At the horizontal direction, the isolation width is set at $30 \mathrm{~cm}$, so the horizontal radius is $10 \mathrm{~cm}, 20 \mathrm{~cm}, 30 \mathrm{~cm}$, and the depth is $10-30 \mathrm{~cm}$. The nitrate nitrogen in the soil is collected from fresh soil. The remaining soil samples are air-dried and screened with $1 \mathrm{~mm}$ filter.

\section{Measurements of carbon, nitrogen and phosphorus in soil nearby crop root zone Determination of carbon element}

The organic carbon in the soil is measured by the potassium dichromate-dilution method (Liu and Rubæk, 2015). The basic principle is to oxidize the organic matter with the heat generated by the rapid mixing of concentrated sulfuric acid and potassium dichromate. The remaining potassium chromate is titrated with ferrous sulfate and the amount of organic carbon is calculated from the amount of potassium dichromate consumed. The specific steps are as follows: accurately weigh $0.5000 \mathrm{~g}$ of soil sample in a $500 \mathrm{ml}$ conical flask; accurately add $10 \mathrm{ml}$ of $1 \mathrm{~mol} / \mathrm{L}\left(1 / 6 \mathrm{~K}_{2} \mathrm{CR}_{2} \mathrm{O}_{7}\right)$ solution to the soil sample and rotate the bottle to mix well; then add concentrated sulfuric acid $(20 \mathrm{ml})$ and slowly shake the flask for $1 \mathrm{~min}$ to promote mixing of reagents and soil; place the flask on asbestos board for about $30 \mathrm{~min}$, dilute with water to $250 \mathrm{ml}$; add 3-4 drops of o-phenanthroline indicator, titrate with ferrous sulfate standard solution until the color of solution turns from green to dark green; ferrous sulfate is added dropwise until brick-red appears.

Calculation method:

$$
\begin{aligned}
& c\left(V_{0}-V\right) \times 10^{-3} \\
& \operatorname{Organic} \operatorname{carbon}(g / \mathrm{kg})=\frac{\times 3.0 \times 1.33}{\text { Weight of dried soil }} \times 1000 \text { (1) }
\end{aligned}
$$

The number 1.33 in the equation (1) is the oxidation correction coefficient. $\mathrm{C}$ is the concentration of $0.5 \mathrm{~mol} / \mathrm{L}$ ferrous sulfate standard solution.

\section{Determination of nitrogen element}

Nitrate nitrogen and alkali-hydrolyzed nitrogen in soil are determined by the determination method in the book named Soil Analysis. Nitrate nitrogen in soil is determined with phenol disulfonic acid colorimetric method, the basic principle is that nitrate nitrogen in the solution extracted from soil can react with phenol disulfonic acid agent under the conditions of anhdrous drying to generate nitrophenoldisulfonic acid. The specific steps are: (1) Extraction. A $50 \mathrm{~g}$ of fresh soil sample is weighed and put into a $500 \mathrm{ml}$ conical flask, $0.5 \mathrm{~g} \mathrm{CaSO} \bullet_{4} \cdot 2 \mathrm{H}_{2} \mathrm{O}$ and $250 \mathrm{ml}$ of water are added, then, the flask is shake on a shaker for $10 \mathrm{~min}$. After resting for $5 \mathrm{~min}$, the supernatant of the suspension is filtered with dry filter paper and the clear filtrate is collected in a dry clean flask (Oliveira and Lacerda, 2014). If the filtrate is colored due to organic matter, it can be removed by adding activated carbon. (2) Determination. A $20-50 \mathrm{ml}\left(\mathrm{NO}_{3}-\mathrm{N} 20-50 \mu \mathrm{g}\right)$ of serum is aspirated in a porcelain evaporating dish, and $0.05 \mathrm{~g}$ of calcium carbonate is added. The dish evaporates on a water bath. After cooling, $2 \mathrm{ml}$ of phenol disulfonic acid reagent is added quickly, and the porcelain evaporating dish is rotated to allow the reagent to come into contact with all dried product. After allowing it to fully act for $10 \mathrm{~min}, 20 \mathrm{ml}$ of water is added and stirred with a glass rod until the dried product completely dissolves. After cooling, 1: $1 \mathrm{NH}_{4} \mathrm{OH}$ is slowly added until the solution is slightly alkaline (yellowish) and then $2 \mathrm{ml}$ is added to ensure 
excessive reagent. Then the solution is transferred to a $100 \mathrm{ml}$ volumetric flask and water is added to make $100 \mathrm{ml}$. In the spectrophotometer, a color cuvette with a radius of $1 \mathrm{~cm}$ is used at the wavelength of, with a blank solution as a reference to adjust the zero point of the instrument.

Calculation method:

Nitrate nitrogen content in soil

$$
(m g / k g)=\rho\left(\mathrm{NO}_{3}^{-}-\mathrm{N}\right) \times V \times t s / m
$$

Wherein, $\rho\left(\mathrm{NO}_{3}^{-}-\mathrm{N}\right)$ - the mass concentration of color nitrate nitrogen found on the standard curve $(\mu \mathrm{g} / \mathrm{ml})$, where $\mathrm{V}$ is the volume of color nitrate nitrogen $(\mathrm{ml})$, ts is the fraction, and $\mathrm{m}$ is the mass $(\mathrm{g})$ of the dried product.

Alkali-hydrolyzed nitrogen in soil is determined using alkaline solution diffusion method, the principle is: in the diffusion plate, $1.0 \mathrm{~mol} / \mathrm{LNaOH}$ is utilized to hydrolyze the soil so that easily hydrolyzed nitrogen solution is converted into $\mathrm{NH}_{3}$, and diffused $\mathrm{NH}_{3}$ is adsorbed by $\mathrm{H}_{3} \mathrm{BO}_{3}$. The $\mathrm{NH}_{3}$ in the absorption solution $\mathrm{H}_{3} \mathrm{BO}_{3}$ is then titrated with a standard acid to calculate the alkali-hydrolyzed nitrogen content in the soil. The specific procedures are: weigh $2.00 \mathrm{~g}$ of air-dried soil sample, place it in the outer chamber of a clean diffusion dish, gently rotate the diffusion dish, and evenly tile the soil sample; take boric acid indicator solution $2 \mathrm{ml}$, place it in the interior of the diffusion plate, then apply alkaline glue on the edge of the diffuser outer chamber, cover it with the frosted glass, and rotate several times to fully adhere the edge of the dish to the frosted glass (Wang and Li, 2016); then gradually open the side of the frosted glass, expose a slit in the outer chamber of the diffusion chamber, quickly add $10 \mathrm{ml}$ of $1 \mathrm{~mol} / \mathrm{LNaOH}$ solution, immediately cover tightly, and rotate the diffusion dish gently, and let the alkali cover all the soil; afterwards, tighten the rubber band to fix the frosted glass, and place it in an incubator of 39 to $14^{\circ} \mathrm{C}$, remove after 23.5 to 24.5 hours, and the $\mathrm{NH}_{3}$ in the absorbent of inner chamber is titrated with $0.0051 \mathrm{~mol} / \mathrm{L}\left(1 / 2 \mathrm{H}_{2} \mathrm{SO}_{4}\right)$ or standard solution.

\section{Calculation method:}

Alkali-hydrolyzed nitrogen content in soil

$(m g / k g)=\frac{c\left(\mathrm{~V}-\mathrm{V}_{0}\right) \times 14.0}{m} \times 10^{3}$

Where: $\mathrm{c}$ is the concentration of the $0.005 \mathrm{~mol} / \mathrm{L}\left(1 / 2 \mathrm{H}_{2} \mathrm{SO}_{4}\right)$ standard solution mol/L, $\mathrm{V}$ is the volume of used $0.005 \mathrm{~mol} / \mathrm{L}\left(1 / 2 \mathrm{H}_{2} \mathrm{SO}_{4}\right)$ standard solution $(\mathrm{ml})$ when the sample is titrated, and is the volume of sed $0.005 \mathrm{~mol} /$ $\mathrm{L}\left(1 / 2 \mathrm{H}_{2} \mathrm{SO}_{4}\right)$ standard solution $(\mathrm{ml})$ when blank solution is titrated. 0 standard solution volume $(\mathrm{ml}) .14 .0$ represents the Molar Mass of nitrogen $(\mathrm{g} / \mathrm{mol}, \mathrm{M}$ is the mass of the sample, and is the conversion factor.

\section{Determination of phosphorus element}

The principle of determination is that the orthophosphate ion in the sample solution react with phthalocyanone reagent in the acidic medium to generate the precipitation of yellow phosphomolybdic acid quinoline, and the phosphorus content is determined by phosphomolybdic acid quinoline gravimetric method (Wang and Kang, 2015).

The determination method is to weigh the sample and place into a $250 \mathrm{ml}$ volumetric flask, add $0.1 \mathrm{~mol} / \mathrm{L}$ nitric acid solution $50 \mathrm{ml}$ and dilute to the volume and mix, filter and discard the initial filtrate, measure $10 \mathrm{ml}$ of the filtrate, then add $10 \mathrm{ml}(1+1)$ nitric acid, dilute to $100 \mathrm{ml}$ with water, boil and add $35 \mathrm{ml}$ quinoa molybdenum reagent, then boil it for $1 \mathrm{~min}$ and keep it in a boiling water bath, and dry in a preheated oven of $178^{\circ} \mathrm{C}$ to $182^{\circ} \mathrm{C}$ for 45 minutes. In the end, an inspection test is conducted.

Scope of application: this method is suitable for the liquid or solid water-soluble fertilizers with the addition of moderate number of secondary elements or trace elements, not suitable for compound fertilizers and solid fertilizers made with chemical methods.

\section{RESULTS}

\section{Changes in carbon content under different irrigation conditions}

The effect of irrigation amount on carbon in soil is more obvious in July and smaller in October, as shown in Fig. 2 (a) and (b). Carbon content in different soil layers under W1 and W2 treatment in July is significantly lower than other treatments, the average is $2.56 \%$ and $3.89 \%$, respectively; the W3, W4, and W5 treatments have no significant difference in content of soil obtained from $0-10 \mathrm{~cm}$ (Ghazaryan and Chen, 2016), with an average of $5.55 \%, 6.16 \%$, and $5.98 \%$, respectively. In October, the carbon content of W1 to W5 is $2.03 \%, 2.37 \%, 2.75 \%, 2.81 \%$, and $3.21 \%$, respectively. Below the $10 \mathrm{~cm}$ soil layer, the W5 treatment has the highest carbon content, while in the $40-50 \mathrm{~cm}$ soil layer, W1 treatment has the lowest carbon content, while the other soil layers have less significant differences.

\section{Changes of nitrate nitrogen content}

In July, the average nitrate content of W1 to W5 is 4.7, $4.5,3.7,1.5$, and $0.8 \mathrm{mg} / \mathrm{kg}$, respectively, which is $70.9 \%$, $71.7 \%, 77.1 \%, 90.9 \%$ and $95.3 \%$ lower than the initial value $(16.1 \mathrm{mg} / \mathrm{kg})$ as shown in Fig. 3(a). With the increase of irrigation amount, the nitrate nitrogen content in soil nearby root zone decreases significantly (Bowles and 
Barrios-Masias, 2016). Compared with W1 treatment, nitrate content in $0-10 \mathrm{~cm}$ soil layer decreases by $21.7 \%$, $19.7 \%, 19.7 \%$ and $58 \%$, respectively, after increasing irrigation amount. There is no significant difference in nitrate nitrogen content between W1 and W2 treatments below $10 \mathrm{~cm}$, but contents are significantly higher than W4 and W5 treatments.

In October, the average values of nitrate content in different treatments decrease by $70.9 \%, 78.4 \%, 94.6 \%$, and $92.4 \%$, respectively, compared with the initial value. With the increase of irrigation amount, W1 has the highest content in $0-10 \mathrm{~cm}$ soil layer, but it only has small difference with W2 and W5. Nitrate nitrogen content of each treatment has small difference in the $10-20 \mathrm{~cm}$ soil layer as well. The nitrate nitrogen content in the soil treated with W1 and W2 below $20 \mathrm{~cm}$ soil layer is significantly higher $(\mathrm{Li}$ and $\mathrm{Pu}$, 2014). It can be seen that the content of nitrate nitrogen in soil nearby root zone of Calligonummongolicum seedlings has a significant decrease trend. After increasing the irrigation amount, the decreasing trend is more obvious.
Changes of alkali-hydrolyzed nitrogen content

It can be seen from Fig. 4 that irrigation in July has a tendency to reduce the content of ammonium nitrogen in the soil profile, which is obvious under W5 treatment. The average ammonium nitrogen content of W1 and W5 treatments is $0.50,0.43,0.44,46$, and $0.20 \mathrm{mg} / \mathrm{kg}$, respectively, which is decreased by $18.7 \%, 30.1 \%, 28.0 \%, 24.6 \%$ and $67.7 \%$ compared with the initial value $(0.61 \mathrm{mg} / \mathrm{kg})$. In addition, the ammonium nitrogen in the soil profile is also reduced to varying degrees after increasing irrigation amount in October (Sun, 2017), which is more pronounced in W3 and W4 treatments. The average ammonium content of W1 to W5 treatment is reduced by $21.9 \%, 20.3 \%, 68.4 \%, 69.6 \%$ and $51.6 \%$, respectively, from the initial values.

\section{Changes of phosphorus content}

The difference of phosphorus content in different soil layers under the drought treatment in July is small, and it decreases in different degrees after the increase of irrigation amount (Armitage and Ho, 2014). The average phosphorus content in the soil profile of W1 to W5 treatment is $1.74,1.68,1.64$, $1.53,1.53 \mathrm{~g} / \mathrm{kg}$, respectively, and is increased by $14.2 \%, 11$.

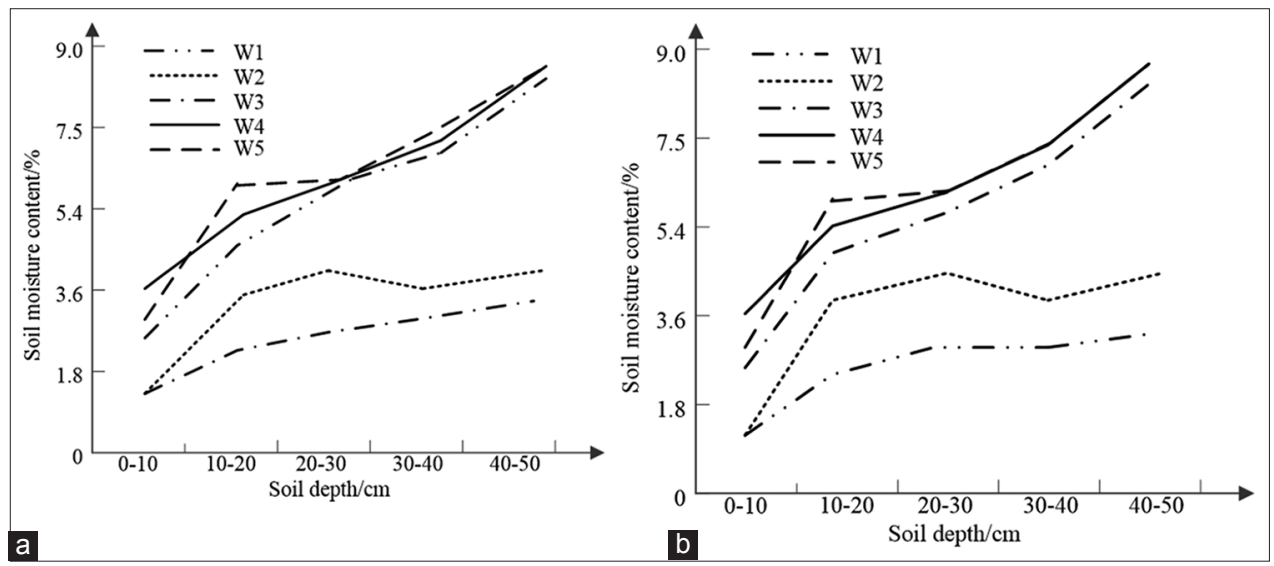

Fig 2. Soil moisture content was different under different irrigation treatments (a) differences in soil moisture content in july, (b) soil moisture ciontent was different in october.

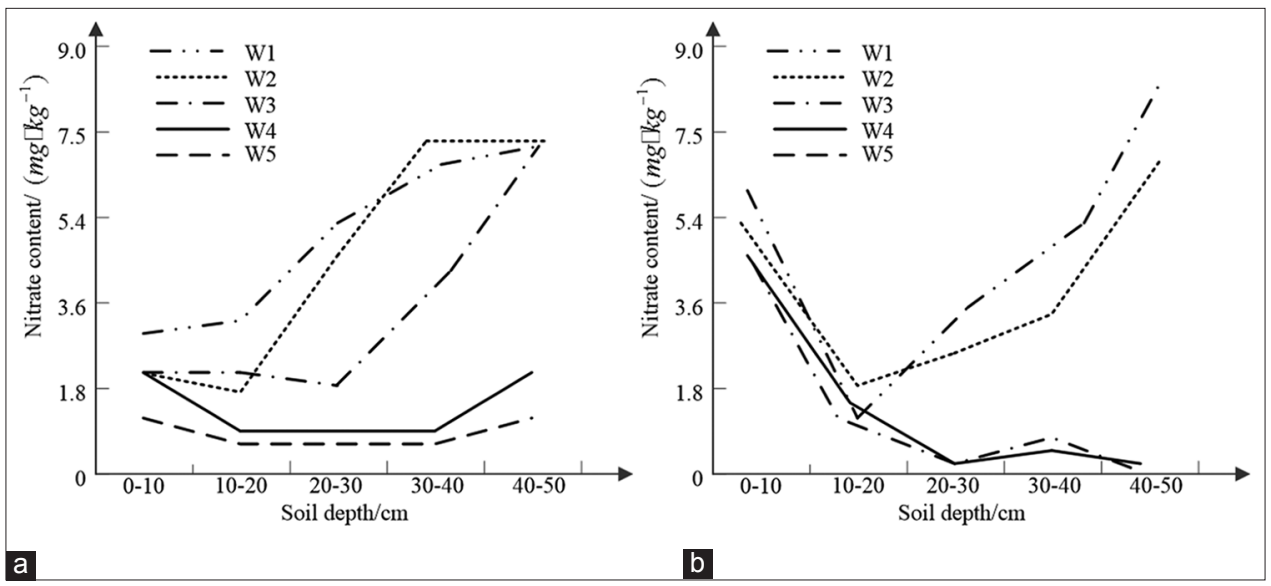

Fig 3. Difference of nitrate nitrogen content in soil under different irrigation water (a) soil nitrate nitrgen content in july, (b) soil nitrate content in october. 
$3 \%, 9.0 \%, 2.7 \%$, and $2.4 \%$, respectively compared to the initial value $(1.49 \mathrm{~g} / \mathrm{kg})$. In addition, other than the high content of surface phosphorus in October, the difference is not significant in other soil samples (Pramanik and Gao, 2017). The change in phosphorus content is also small with increasing irrigation amount, but the content in the soil layer below $20 \mathrm{~cm}$ is reduced when treated with W5. The average phosphorus content in the soil profile is 1.58, 1.60, 1.56, 1.61 , and $1.48 \mathrm{~g} / \mathrm{kg}$, respectively, and the changes is $5.96 \%$, $7.06 \%, 4.48 \%, 8.07 \%$, and $-0.59 \%$, respectively. It can be seen that the phosphorus content in soil nearby the root zone of the jujube plant grows, but excessive irrigation at the end of the season tends to reduce it.

\section{CONCLUSION}

\section{Effects of brackish irrigation water with different salinity on carbon content}

Variance analysis of organic carbon content in soil nearby the root area of jujube trees is shown in Table 4. From the experimental data, it can be seen that the coefficient of variation of each treatment generally shows an increasing trend compared with the control. The difference in the magnitude of change in different treatments is also greater. The reason for the increase in the coefficient of variation is that brackish water irrigation inhibits the absorption and utilization of organic carbon in the root cells of jujube trees, resulting in an increase in the organic carbon content in soil. In addition, different amounts of fertilizer and irrigation water also have an impact on the distribution of organic carbon in soil.

When the salt amount in brackish irrigation water is $2 \mathrm{~g} / \mathrm{L}$, that is, treatment 2,6 , and 7 , the variation coefficient of organic carbon in soil nearby root zone is relatively small, and the change of organic carbon is relatively stable, indicating that the adsorption of the root of jujube trees for organic carbo is stable. Because of the same treatment with single organic fertilizer, the difference in the amount of irrigation water leads to a difference in the coefficient of variation between three treatments. That is, the larger the amount of irrigation, the larger the coefficient of variation. The differences are 41\%,45\%and 61\% respectively. And

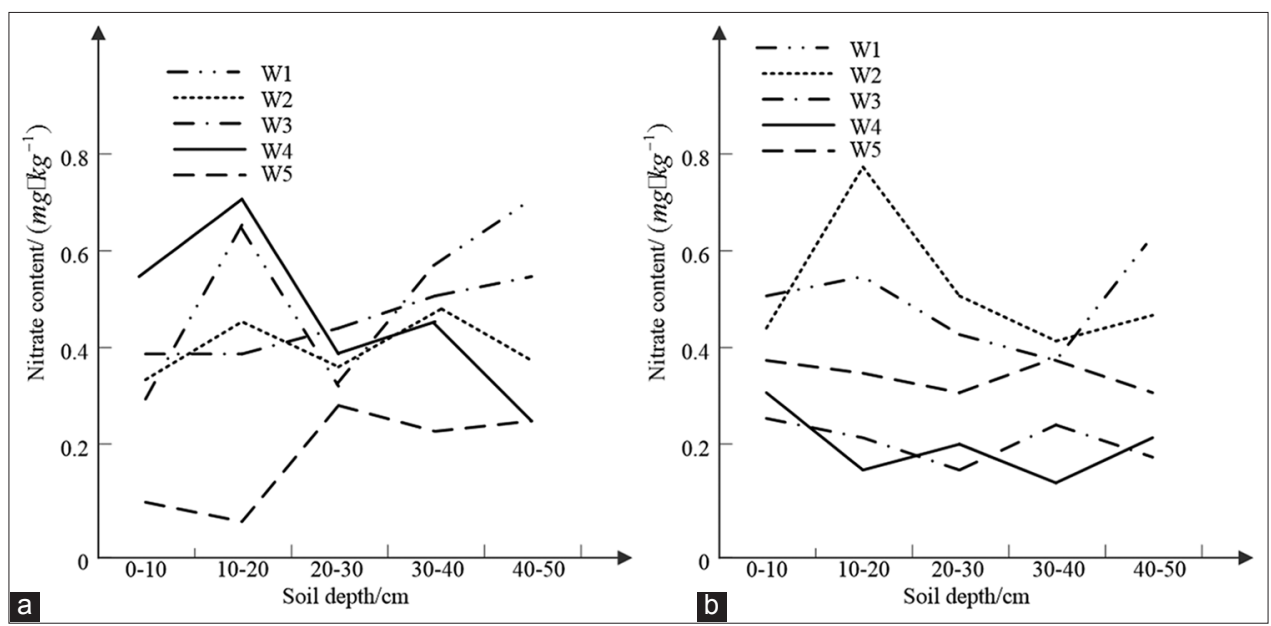

Fig 4. The content of ammonium nitrogen in soil was different under different irrigation (a) the nitrgen content of soil was different in july, (b) the nitrogen content of soil was different in october.

Table 4: The table of various processing soil organic carbon content anova

\begin{tabular}{|c|c|c|c|c|c|}
\hline Processing code & $\begin{array}{c}\text { Range of } \\
\text { measurement }(\mathrm{g} / \mathrm{kg})\end{array}$ & The average $(\mathrm{g} / \mathrm{kg})$ & The variance $(\mathrm{g} / \mathrm{kg})$ & $\begin{array}{c}\text { The standard } \\
\text { deviation }(\mathrm{g} / \mathrm{kg})\end{array}$ & $\begin{array}{l}\text { Coefficient of } \\
\text { variation (\%) }\end{array}$ \\
\hline 10 Lcontrast & $14.44-7.24$ & 9.97 & 13.05 & 3.61 & 36.21 \\
\hline 20 Lcontrast & $13.83-3.92$ & 10.34 & 17.91 & 4. 15 & 40.14 \\
\hline 30 Lcontrast & $15.20-7.66$ & 11.21 & 20.76 & 4.56 & 46.68 \\
\hline 1 & $18.52-8.28$ & 12.7 & 81.07 & 9 & 70.89 \\
\hline 2 & $13.31-5.63$ & 9.41 & 50.2 & 7.09 & 75.29 \\
\hline 3 & $24.24-9.28$ & 15.38 & 249.6 & 14.82 & 96.35 \\
\hline 4 & $21.10-7.97$ & 13.58 & 143.29 & 11.97 & 88.15 \\
\hline 5 & $20.45-9.62$ & 14.35 & 111.49 & 10.56 & 73.58 \\
\hline 6 & $14.63-7.10$ & 10.44 & 50.59 & 7.11 & 68.13 \\
\hline 7 & $11.76-5.17$ & 7.95 & 28.92 & 5.38 & 67.64 \\
\hline 8 & $2351-10.42$ & 15.7 & 155.41 & 12.47 & 79.4 \\
\hline 9 & $21.70-8.05$ & 13.99 & 153.44 & 12.39 & 88.54 \\
\hline
\end{tabular}


thus reflecting that the greater the amount of irrigation, the more water that can move in the soil, the more significant the change of organic carbon in soil with water migration.

When the salinity of irrigation water is $3 g / L$, that is, treatment 3, 4 and 9, the coefficient of variation is relatively large, which means that with the increase of salt amount, the content of salt in the roots of jujube tree increases, which increases the degree of salt stress, impeding the absorption of carbon by the root system, so as to greatly reduce the turnover rate of carbon in soil, resulting in a change in the stability of the carbon.

When the salinity of irrigation water is $4 g / L$,that is, treatment 1, 5 and 8. From Table 4, it can be seen that as the salinity of irrigation water continues to increase, its coefficient of variation appears to decrease. It may be because with the increase of salinity, the activity of organic microbes in soil will be weakened and the effective input of organic carbon in soil will be reduced. This requires further analysis.

\section{Effects of brackish irrigation water with different salinity on nitrate nitrogen content}

Table 5 gives the analysis of the variance of nitrate nitrogen content in soil of various treatments. The analysis table shows that the nitrate content in soil treated by different tests varies between $23 \mathrm{mg} / \mathrm{kg} /-65 \mathrm{mg} / \mathrm{kg}$ and the range of change is relatively large. In order to better reflect the difference in nitrate nitrogen content variation in soil between treatments, the coefficient of variation, that is the ratio of the standard deviation to the average, is introduced. As can be seen from the table, the coefficient of variation of nitrate nitrogen content in all treated soils is greater than the initial soil content, indicating that quantity of brackish water irrigation and fertilizer with different salinity affect nitrate nitrogen content in soil (Nirmala K \& Ramesh R 2016). The greater the coefficient of variation, the greater the influence from the outside world.

Effects of brackish irrigation water with different salinity on distribution of alkali- hydrolyzed nitrogen

The results of the variance analysis of the content of alkalihydrolyzed nitrogen in soil nearby root zone are shown in Table 6. From the data in the table, alkali-hydrolyzed nitrogen content in soil is in the range of $42-70 \mathrm{mg} / \mathrm{kg}$. The result is: the coefficient of variation of each treatment displays an increasing trend compared to the control group, indicating that the effect of excessive salinity in irrigation water on alkali-hydrolyzed nitrogen content in soil cannot be ignored (Svanbäck A \&Ulén B 2014).

Table 5: The table of various processing soil nitric nitrogen content anova

\begin{tabular}{|c|c|c|c|c|c|}
\hline Processing code & $\begin{array}{c}\text { Range of } \\
\text { measurement }(\mathrm{g} / \mathrm{kg})\end{array}$ & The average $(\mathrm{g} / \mathrm{kg})$ & The variance $(\mathrm{g} / \mathrm{kg})$ & $\begin{array}{c}\text { The standard } \\
\text { deviation }(\mathrm{g} / \mathrm{kg})\end{array}$ & $\begin{array}{l}\text { Coefficient of } \\
\text { variation (\%) }\end{array}$ \\
\hline 10 Lcontrast & $43.506-24.797$ & 32.344 & 68.692 & 8.29 & 30.06 \\
\hline 20 Lcontrast & $58.792-19.504$ & 33.929 & 128.889 & 11.35 & 33.46 \\
\hline 30 Lcontrast & $52.325-22.049$ & 38.191 & 147.237 & 12.13 & 35.68 \\
\hline 1 & $68.142-31.272$ & 46.682 & 1132.153 & 33.65 & 72.07 \\
\hline 2 & $46.637-28.520$ & 37.062 & 231.582 & 15.22 & 53.1 \\
\hline 3 & $77.372-42.613$ & 60.787 & 943.243 & 30.71 & 50.52 \\
\hline 4 & 74.394-34.092 & 59.389 & 964.34 & 31.05 & 52.3 \\
\hline 5 & 67.346-32.094 & 46.395 & 1028.617 & 32.07 & 69.13 \\
\hline 6 & $48.394-28.416$ & 36.604 & 371.691 & 19.28 & 53.11 \\
\hline 7 & $42.122-24.891$ & 32.265 & 293.635 & 17.14 & 52.67 \\
\hline 8 & $85.796-47.287$ & 64.978 & 1358.986 & 36.86 & 76.3 \\
\hline 9 & $62.033-27.830$ & 41.477 & 1001.732 & 31.65 & 56.73 \\
\hline
\end{tabular}

Table 6: The table of Various processing soil Alkaline Nitrogen content anova

\begin{tabular}{|c|c|c|c|c|c|}
\hline Processing code & $\begin{array}{c}\text { Range of } \\
\text { measurement }(\mathrm{g} / \mathrm{kg})\end{array}$ & The average $(\mathrm{g} / \mathrm{kg})$ & The variance $(\mathbf{g} / \mathbf{k g})$ & $\begin{array}{c}\text { The standard } \\
\text { deviation }(\mathrm{g} / \mathrm{kg})\end{array}$ & $\begin{array}{l}\text { Coefficient of } \\
\text { variation }(\%)\end{array}$ \\
\hline 10 Lcontrast & $54.70-19.7$ & 39.66 & 159.48 & 12.63 & 31.85 \\
\hline 20 Lcontrast & $57.17-25.00$ & 37.62 & 207.68 & 14.41 & 38.31 \\
\hline 30 Lcontrast & $64.40-35.65$ & 48.56 & 429. 62 & 20.73 & 42.68 \\
\hline 1 & 83.83-48.36 & 63.21 & 1016. 46 & 31.88 & 50.44 \\
\hline 2 & $71.06-31.69$ & 52.91 & 1208. 07 & 34. 76 & 65.69 \\
\hline 3 & $94.50-41.88$ & 68.66 & 2265. 37 & 47.6 & 69.32 \\
\hline 4 & $95.13-47.19$ & 68.54 & 2157.48 & 46.45 & 67.77 \\
\hline 5 & $80.41-36.56$ & 65.53 & 1274.57 & 35.7 & 54.48 \\
\hline 6 & $67.66-24.08$ & 48.39 & 1180.04 & 34.35 & 70.98 \\
\hline 7 & $64.48-23.85$ & 48.45 & 1008. 35 & 31.75 & 65.54 \\
\hline 8 & $56.00-26.69$ & 42.13 & 591.65 & 24.32 & 56.73 \\
\hline 9 & $78.59-40.32$ & 57.72 & 1535. 84 & 39.19 & 67.9 \\
\hline
\end{tabular}




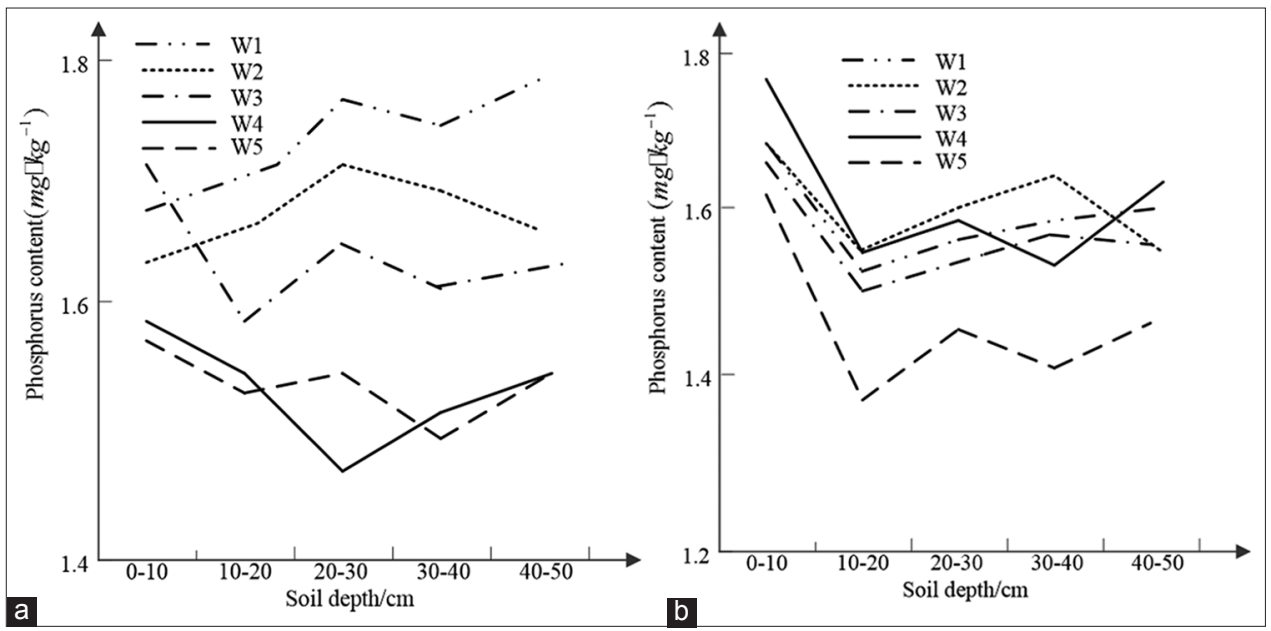

Fig 5. The phosphorus content of soil was different under different irrigation (a) phosphorus content in soil was different in july, (b) differences in phosphorus in soil in october.

When the salinity of irrigation water is $2 g / L$, the average coefficient of variation of alkali-hydrolyzed nitrogen in soil is $67.40 \%$, which is relatively large compared to the control. It may be that the salt content in soil nearby root zone of the jujube tree increases during brackish water irrigation, which makes the root of the jujube tree is impeded by salt stress and the absorption of alkali-hydrolyzed nitrogen is further hindered, resulting in the accumulation of alkalihydrolyzed nitrogen in soil. When the salinity of irrigation water is $3 \mathrm{~g} / \mathrm{L}$, the average coefficient of variation is $66.71 \%$, which is smaller than when the salinity of irrigation water is $2 \mathrm{~g} / \mathrm{L}$. When the salinity of irrigation water is, $4 \mathrm{~g} / \mathrm{L}$ the coefficient of variation is $53.88 \%$, which is different from the change of nitrate nitrogen and organic carbon in soil.

From the above, we can see that salinity has a great impact on alkali-hydrolyzed nitrogen in soil, and at the same time, the amount of irrigation and fertilizer also have influence on alkali-hydrolyzed nitrogen in soil. The effect of salinity on alkali-hydrolyzed nitrogen in soil is not constant, and the effect of salinity on alkali-hydrolyzed nitrogen should have a threshold (De Borba B M \& Jack R F 2014), but the specific value of this threshold has yet to be determined by a large amount of experimental data in the future.

\section{Effects of brackish irrigation water with different salinity on distribution of phosphorus}

Brackish water with different salinity can affect the content of phosphorus in soil. Through analysis of the vertical changes in the whole growth period of each treatment, it can be known from the comparison that the content of phosphorus in soil under brackish water treatment varies by a wide margin. The phosphorus content of soil was different under different irrigation is shown as Fig. 5.

According to the vertical changes in the whole growth period of the plants, it can be concluded that the low salt can promote the increase of phosphorus content in soil and can increase the activity of phosphorus. Compared with the control, the phosphorus content is higher than that of the control at $2 \mathrm{~g} / \mathrm{L}$. The overall content in the flowering and fruit setting period of the jujube tree grows to its maximum, and the phosphorus activity is the strongest. But in the fruit ripening period, the phosphorus content decreases. This change in the whole growth period is mainly affected by climatic factors, when the temperature is high, the activity of phosphorus is also the most active, with the fall in temperature, and phosphorus activity is also weakened. At $3 \mathrm{~g} / \mathrm{L}$ salinity, the phosphorus activity is suddenly increased at the initial stage of the experiment, ie, at the early germination stage, and then is decreased significantly. Finally, in the fruit ripening period, the phosphorus activity is slightly enhanced. The change trend of soil phosphorus activity at the initial stage of the experiment under $4 \mathrm{~g} / \mathrm{L}$ salinity is different from that of $3 \mathrm{~g} / \mathrm{L}$ salinity, and then shows a high degree of consistency. As salinity continues to increase, the concentration of solution in the soil continues to increase, and the number of microorganism's changes, resulting in changes in the stability of phosphorus. The unstable change of phosphorus is only transient, and then it is stabilized. This shows that the phosphorus in soil has a constant protection capacity, which is consistent with the book, named research of phosphorus in soil, written by GuanSongyin. During the treatment with $3 \mathrm{~g} / \mathrm{L}$ and $4 \mathrm{gL}$ salinity, the phosphorus activity changes greatly in the short term and then tends to a stable state, which is due to the resistance of the phosphorus activity to the external environment.

Effects of brackish irrigation water with different salinity on the yield of jujube tree

The brackish water irrigation with proper amount of salt will increase the effective utilization of carbon, nitrogen and phosphorus in soil, so that the jujube tree can achieve high yield. In order to select the optimal test index, 
Table 7: The results of Orthogonal test

\begin{tabular}{lcccc}
\hline The serial number & Irrigation quota (L/plant) & Salinity (g/L) & Apply fertilizer (Temperature) & Yield (kg) \\
\hline 1 & 1 & 3 & 3 & 0.734 \\
2 & 2 & 1 & 2 & 0.718 \\
3 & 3 & 2 & 3 & 1.314 \\
4 & 1 & 2 & 1 & 0.841 \\
5 & 2 & 3 & 1 & 0.902 \\
6 & 3 & 1 & 2 & 0.795 \\
7 & 1 & 1 & 3 & 0.459 \\
8 & 2 & 3 & 1.972 & 0.925 \\
9 & 3 & 2 & 3.057 & -3.452 \\
K1 & 2.034 & 1.972 & 3.088 \\
K2 & 2.522 & 3.607 & 0.657 \\
K3 & 3.561 & 2.538 & 1.019 \\
K1 & 0.678 & 0.657 & 1.029 \\
K2 & 0.841 & 1.202 & - \\
K3 & 1.187 & 0.846 & 0.372 \\
Range & 0.509 & 0.545 & C3 \\
Optimal scheme & A3 & B3 & - \\
\hline
\end{tabular}

according to the yield, the irrigation quota, irrigation water salinity and fertilization scheme are analyzed, and the test results are analyzed using the quasi-horizontal orthogonal design of $L_{9}\left(3^{3}\right)$, shown in Table 7.

It can be seen that the factor $B$, that is, salinity, has the greatest impact on the test. The first level is the best $(3 \mathrm{~g} / \mathrm{L}$ salt irrigation); followed by the factor A, ie., the irrigation quota, and the third level is good (ie., the irrigation volume is $30 \mathrm{~L} /$ plant). The last factor $\mathrm{C}$ is the fertilization factor, and the third level is good (ie., optimized fertilization). In general, the optimal plan obtained from the table for this experiment should be A3B3C3, which is the $9^{\text {th }}$ treatment.

\section{CONCLUSION}

With the increase of salinity of irrigation water, the dynamic change of organic carbon content in soil nearby root zone of jujube tree during the whole growth period is more obvious. Through the correlation analysis between soil salinity and organic carbon nearby the root area during the whole growth period, we can see that salinity of soil and organic carbon when treated with brackish water with different salinity can maintain good correlation. At the same time, the significance of the fitted model equation is tested. It is found that the error between the predicted value and the measured value is within $10 \%$, indicating that the established model equation is reliable. The vertical variation of nitrate nitrogen and alkali-hydrolyzed nitrogen is consistent at all growth stages, and they both decrease with the growth period under low salinity and increase under high salinity. The contents of them in the top layer soil are the largest, and the content gradually decreases with the depth. The analysis of the established model equation shows that the phosphorus content has a good correlation with soil salinity under irrigation treatment low salinity, and its correlation gradually decreases with the increase of salinity.

\section{REFERENCES}

Ahamed, A. J., K. Loganathan, S. Ananthakrishnan, J. Ahmed and M. A. Ashraf. 2017. Evaluation of graphical and multivariate statistical methods for classification and evaluation of groundwater in alathur block, Perambalur District, India. Appl. Ecol. Environ. Res. 15(3): 105-116.

Armitage, A. R., C. K. Ho and E. N. Madrid. 2014. The influence of habitat construction technique on the ecological characteristics of a restored brackish marsh. Ecol. Eng. 62(1): 33-42.

Atikuzzamman, M., M. A. Islam, M. Moniruzzaman and M. S. Islam. 2018. Vendors and consumers status and microbiological analysis of some common fast food items of different fast food restaurants in Barisal City. Malays. J. Halal Res. 1(1): 17-21.

Biswas, J. K. 2018. A few words on black rice. Malays. J. Halal Res. 1(1): $1-2$.

Bowles, T. M., F. H. Barrios-Masias and E. A. Carlisle. 2016. Effects of arbuscular mycorrhizae on tomato yield, nutrient uptake, water relations, and soil carbon dynamics under deficit irrigation in field conditions. Sci. Total Environ. 566-567: 1223-1234.

Camara, E. M., E. P. Caramaschi, F. Di Dario and A. C. Petry. 2018. Short-term changes in two tropical coastal lagoons: Effects of sandbar openings on fish assemblages. J. Coast Res. 34(1): 90-105.

Chmelíková, L. and M. Hejcman. 2014. Effect of nitrogen, phosphorus and potassium availability on emergence, nodulation and growth of Trifolium medium L. in alkaline soil. Funct. Plant Biol. 16(4): 717-25.

De Borba, B. M., R. F. Jack and J. S. Rohrer. 2014. Simultaneous determination of total nitrogen and total phosphorus in environmental waters using alkaline persulfate digestion and ion chromatography. J. Chromatogr. A. 1369: 131-137.

Ghazaryan, K. and Y. Chen. 2016. Hydrochemical assessment of surface water for irrigation purposes and its influence on soil salinity in Tikanlik oasis, China. Environ. Earth Sci. 75(5): 1-15.

Herrera-Franco, T., N. Gavín-Quinchuela, P. Alvarado-Macancela and 
Carrión-Mero. 2017. Participative analysis of socio-ecological dynamics and interactions. A case study of the manglaralto coastal aquifer, Santa Elena-Ecuador. Malays. J. Sustain. Agric. 1(1): 19-22.

Khajanchi, L., P. S. Minhas and R. K. Yadav. 2015. Long-term impact of wastewater irrigation and nutrient rates II. Nutrient balance, nitrate leaching and soil properties under peri-urban cropping systems. Agric. Water Manage. 156: 110-117.

Kniat, A. 2017. Visualization of a lifeboat motion during lowering along ship's side. Pol. Marit. Res. 24(4): 42-46.

Kumari, K. G., P. Moldrup and M. Paradelo. 2014. Effects of biochar on air and water permeability and colloid and phosphorus leaching in soils from a natural calcium carbonate gradient. J. Environ. Qual. 43(2): 647-657.

Li, C., J. Lei and Y. Zhao. 2015. Effect of saline water irrigation on soil development and plant growth in the Taklimakan Desert highway shelterbelt. Soil Tillage Res. 146: 99-107.

Li, J., L. Pu and M. Zhu. 2014. Evolution of soil properties following reclamation in coastal areas: A review. Geoderma. 226-227(1): 130-139.

Li, Z., C. Han and T. Gu. 2018. Economics of biomass gasification: A review of the current status. Energy Sources B Econ. Plan. Policy. 13(2): 137-140.

Liu, C., G. H. Rubæk and F. Liu. 2015. Effect of partial root zone drying and deficit irrigation on nitrogen and phosphorus uptake in potato. Agric. Water Manage. 159: 66-76.

Nirmala, K., R. Ramesh and N. K. Ambujam. 2016. Geochemistry of surface sediments of a tropical brackish water lake in South Asia. Environ. Earth Sci. 75(3): 1-11.

Nystrand, M. I., P. Österholm and C. Yu. 2016. Distribution and speciation of metals, phosphorus, sulfate and organic material in brackish estuary water affected by acid sulfate soils. Appl. Geochem. 66: 264-274.

Oliveira, S. P. D., N. B. D. Lacerda and S. C. Blum. 2014. Organic carbon and nitrogen stocks in soils of northeastern Brazil converted to irrigated agriculture. Land Degrad. Dev. 26(1): 9-21.

Pramanik, B. K., Y. Gao and L. Fan. 2017. Antiscaling effect of polyaspartic acid and its derivative for RO membranes used for saline wastewater and brackish water desalination. Desalination.
404: 224-229.

Roy, S., G. Handique, F. R. Bora and A. Rahman. 2018. Evaluation of certain non-conventional plant-based oils against red spider mite of tea. J. Environ. Biol. 39(1): 1-4.

Sharma, D. and K. D. Yadav. 2017. Vermicomposting of flower waste: Optimization of maturity parameter by response surface methodology. Malays. J. Sustain. Agric. 1(1): 15-18.

Sultana, T., S. Rahman, N. Naher, R. M. D. Masum, A. H. A. Ahmed and R. Islam. 2018. Performance of fruit vegetables in summer under mahagony based agroforestry systems. Malays. J. Halal Res. 1(2): 8-14.

Sun, W., H. Zhao and F. Wang. 2017. Effect of salinity on nitrogen and phosphorus removal pathways in a hydroponic micro-ecosystem planted with Lythrum salicaria, L. Ecol. Eng. 105: 205-210.

Svanbäck, A., B. Ulén and A. Etana. 2014. Mitigation of phosphorus leaching losses via subsurface drains from a cracking marine clay soil. Agric. Ecosyst. Environ. 184(1): 124-134.

Wang, M., D. Q. Zhang, J. Su, J. W. Dong and S. K. Tan. 2018. Assessing hydrological effects and performance of low impact development practices based on future scenarios modeling. J. Clean. Prod. 179: 12-23.

Wang, Q., C. Lu and H. Li. 2014. The effects of no-tillage with subsoiling on soil properties and maize yield: 12-Year experiment on alkaline soils of Northeast China. Soil Tillage Res. 137(3): 43-49.

Wang, R., Y. Kang and S. Wan. 2015. Effects of different drip irrigation regimes on saline-sodic soil nutrients and cotton yield in an arid region of Northwest China. Agric. Water Manage. 153: 1-8.

Wang, S., T. Li, and Z. Zheng. 2016. Effect of tea plantation age on the distribution of soil organic carbon and nutrient within microaggregates in the hilly region of Western Sichuan, China. Ecol. Eng. 90: 113-119.

Zhang, H., L. Wu and W. Gu. 2016. Effects of different leaching water sources and volume on soil salt and chemical properties in a soil mesocosm experiment. Environ. Earth Sci. 75(8): 1-7.

Zhang, N., C. Zhou, W. Xia and A.V. Nguyen. 2018. Volatilization of mercury in coal during conventional and microwave drying and its potential guidance for environmental protection. J. Clean Prod. 176: 1-6. 